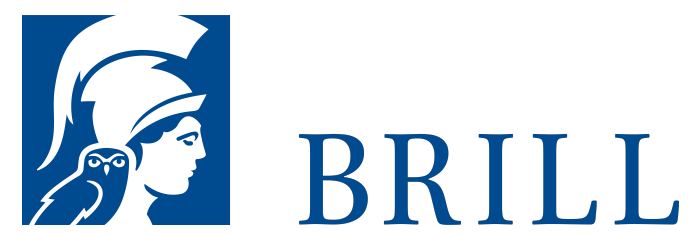

\title{
Intuitionen und apriorische Rechtfertigung
}

\section{Author: Martin Grajner}

Das Thema der apriorischen Rechtfertigung ist ein klassisches philosophisches Thema. Von der Antike bis in die Gegenwart wird ein intensiver Disput darüber geführt, ob man die Existenz nicht-empirischer Formen der Rechtfertigung anerkennen sollte. In diesem Buch wird ein intuitionenbasiertes Modell apriorischer Rechtfertigung entwickelt und verteidigt. Darüber hinaus werden die folgenden Fragen behandelt: Wie sollte man den Begriff der apriorischen Rechtfertigung charakterisieren? Welche Gründe gibt es für die Annahme nicht-empirischer Quellen der Rechtfertigung? Gibt es Alternativen zu intuitionenbasierten Modellen apriorischer Rechtfertigung? Kann man die Wahrheitsförderlichkeit nicht-empirischer Quellen der Rechtfertigung erklären?

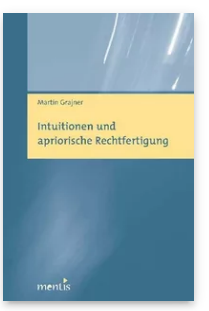

Pages: 185

Seiten

Language:

German

Subjects:

General,

Philosophy

Publisher: Brill | mentis

E-Book (PDF)

Released online:

o1 Jul 2011

ISBN: 978-3-

95743-888-1

List price

USD $\$ 48.00$

Paperback

Publication date:

o1 Jul 2011

ISBN: 978-3-

89785-744-5

List price

USD $\$ 48.00$ 
For more information see brill.com

Order information: Order online at brill.com +44330 333 0049 | customerservices@brill.com Submission information: brill.com/authors

Titles published by Brill | Fink, Brill | mentis or Brill | Schöningh: +49(o)715413279216| brill@brocom.de 